\title{
Reactive Nitrogen Species in Mitochondria and Their Implications in Plant Energy Status and Hypoxic Stress Tolerance
}

OPEN ACCESS

Edited by:

Jeremy Astier,

Helmholtz Zentrum München

Germany

Reviewed by:

Francisca Sevilla,

Agencia Estatal Consejo Superior de Investigaciones Científicas, Spain

Natalia Correa-Aragunde, Instituto de Investigaciones Biológicas

- CONICET, UNMdP, Argentina

${ }^{*}$ Correspondence: Kapuganti Jagadis Gupta jgk@nipgr.ac.in

Specialty section:

This article was submitted to Plant Biotic Interactions, a section of the journal

Frontiers in Plant Science

Received: 11 December 2015 Accepted: 10 March 2016

Published: 24 March 2016

Citation:

Gupta KJ and Igamberdiev AU (2016)

Reactive Nitrogen Species

in Mitochondria and Their Implications in Plant Energy Status and Hypoxic

Stress Tolerance.

Front. Plant Sci. 7:369.

doi: 10.3389/fp/s.2016.00369

\section{Kapuganti Jagadis Gupta ${ }^{*}$ and Abir U. Igamberdiev²}

${ }^{1}$ National Institute of Plant Genome Research, New Delhi, India, ${ }^{2}$ Department of Biology, Memorial University of Newfoundland, St. John's, NL, Canada

Hypoxic and anoxic conditions result in the energy crisis that leads to cell damage. Since mitochondria are the primary organelles for energy production, the support of these organelles in a functional state is an important task during oxygen deprivation. Plant mitochondria adapted the strategy to survive under hypoxia by keeping electron transport operative even without oxygen via the use of nitrite as a terminal electrons acceptor. The process of nitrite reduction to nitric oxide (NO) in the mitochondrial electron transport chain recycles $\mathrm{NADH}$ and leads to a limited rate of ATP production. The produced ATP alongside with the ATP generated by fermentation supports the processes of transcription and translation required for hypoxic survival and recovery of plants. Non-symbiotic hemoglobins (called phytoglobins in plants) scavenge NO and thus contribute to regeneration of $\mathrm{NAD}^{+}$and nitrate required for the operation of anaerobic energy metabolism. This overall operation represents an important strategy of biochemical adaptation that results in the improvement of energy status and thereby in protection of plants in the conditions of hypoxic stress.

Keywords: peroxynitrite, nitric oxide, superoxide, hypoxia, mitochondria

\section{FUNCTIONALITY OF MITOCHONDRIA UNDER HYPOXIC STRESS}

The primary function of mitochondria is to generate ATP, thus these organelles are vital for plant survival. Since oxygen is essential for ATP, any change in its concentration can affect ATP levels; therefore it can affect all energy requirements for biochemical reactions in the cell. Since mitochondria take up oxygen for respiration, these organelles efficiently sense oxygen. Plant tissues, especially roots, experience hypoxia during flooding and waterlogging (Bailey-Serres and Voesenek, 2008). Plants experience hypoxia in roots, germinating and developing seeds and in any bulky tissues due to the restricted diffusion of oxygen into these tissues through internal cell layers (Tschiersch et al., 2011). During hypoxia, cytochrome oxidase (COX) will have a limited capacity to function using oxygen while another terminal oxidase, the alternative oxidase (AOX), practically does not function under hypoxia (Igamberdiev and Hill, 2009). This is due to the different $\mathrm{Km}$ values of these two terminal oxidases. For instance, the $\mathrm{Km}$ value of COX for oxygen is in the range from 0.1 to $0.15 \mu \mathrm{M}$ whereas the $\mathrm{Km}$ value for AOX is in the order of $10 \mu \mathrm{M}$ (reviewed in Igamberdiev and Hill, 2009). The lack of the terminal acceptor alters the 
mitochondrial functionality under hypoxia and near anoxia and results in impairment of the mitochondrial infrastructure (Vartapetian et al., 2003). The direct effect of oxygen deficiency on mitochondria is related to the lack of terminal electron acceptor in the electron transport chain and to the lack of ATP production. We will show below that plant mitochondria may have a sufficient metabolic plasticity to partially overcome these shortcomings, but their operation in such stress conditions is associated with the formation of reactive oxygen and nitrogen species.

\section{PLANT MITOCHONDRIA APPLY VARIOUS STRATEGIES TO SURVIVE UNDER HYPOXIA}

Survival under hypoxia depends on energy production. Therefore it is very important for the cells to safeguard mitochondria during stress. Plant mitochondria adapt various strategies to retain their structure for prolonged periods of time. One of such strategies is to keep the production of ATP under low oxygen conditions. A preliminary clue about the requisition for ATP for structural integrity came from study by Coueé et al. (1992), where the exogenous supply of ATP was shown to result in the support of endogenous ATP production and protection of mitochondria. Later several studies revealed that the application of nitrate has a protective role for root mitochondria from maize and pea seedling (Müller et al., 1994; Vartapetian and Polyakova, 1999). These authors suggested that nitrate $\left(\mathrm{NO}_{3}{ }^{-}\right)$can act as a terminal electron acceptor that supports the operation of electron transport chain in the absence of oxygen. But so far there is no evidence that nitrate can act as a terminal electron acceptor. How nitrate can be transported to mitochondria is also not known. Plants take up nitrate by high and low-affinity transporters (encoded by the families of genes NRT1 and NRT2) (Dechorgnat et al., 2011). After being taken up by roots, $\mathrm{NO}_{3}{ }^{-}$is reduced first to $\mathrm{NO}_{2}{ }^{-}$by the cytosolic nitrate reductase (cNR) where $\mathrm{NAD}(\mathrm{P}) \mathrm{H}$ is used as electron donor, and further the plastidal nitrite reductase reduces nitrite to ammonium (Simontacchi et al., 2015). But there are no reports that mitochondria contain any nitrate transporter. On the other hand, nitrate could indirectly support the functionality of seedling mitochondria under hypoxia via its reduction to nitrite, which can be imported to mitochondria by a similar transporter to that found in chloroplasts (Sugiura et al., 2007) or by the mitochondrial inner membrane anion channel (PIMAC) activated under low ATP conditions (Laus et al., 2008). In potato tuber mitochondria, 29 metabolite transporters have been identified (Salvato et al., 2014), while 58 members of the mitochondrial carrier protein family were described in Arabidopsis (Palmieri et al., 2011), and 50 members in rice (Taylor et al., 2010). Some of these transporters can potentially carry nitrite, however, further studies are needed to establish what particular carrier is used to import nitrite into mitochondria.

The mitochondria of some anoxia-tolerant plant species do not change their structure under anoxia. For instance the mitochondria of anoxia-tolerant plants Echinochloa phyllopogon and E. crus-galli retained their structure and metabolic activity during the prolonged exposure to anaerobic stress (Kennedy et al., 1987). In another study it was shown that the mitochondrial biogenesis did not alter in the anoxia-tolerant rice (Howell et al., 2007). All this suggests that plants can use a specific strategy to survive under hypoxia or anoxia by keeping their mitochondria in a functional state (Gupta and Igamberdiev, 2011; Igamberdiev et al., 2014; Shingaki-Wells et al., 2014).

\section{MITOCHONDRIA CAN REDUCE NITRITE TO NO}

Several lines of evidence suggest that mitochondria of different and maybe all species are capable of reducing nitrite to nitric oxide (NO). For instance, the mitochondria isolated from ciliate protists and Fusarium fungus, possess a capability to reduce nitrite to NO (Tielens et al., 2002). Kozlov et al. (1999) showed that rat liver mitochondria can produce NO using nitrite. The first evidence for this reaction in photosynthetic organisms came from the study of the green alga Chlorella sorokiniana where the addition of nitrite resulted in NO formation and could be blocked by the inhibitors of the mitochondrial electron transport chain (Tischner et al., 2004). Later it was shown that tobacco cell suspensions are able to reduce nitrite to NO and that the application of mitochondrial inhibitors suppressed this reaction (Planchet et al., 2005). Then Gupta et al. (2005) conducted a detailed study and found that nitrite reduction to NO takes place in root mitochondria from various species, such as pea, barley, Arabidopsis and tobacco, and determined the $\mathrm{Km}$ value for nitrite reduction to NO $(175 \mu \mathrm{M})$. This allowed estimating nitrite concentration needed for NO production. Since under hypoxia nitrite reduction to ammonium is inhibited (Botrel et al., 1996), the accumulated nitrite can act as a substrate for NO formation. This reaction is highly sensitive to oxygen, which has a $\mathrm{Ki}$ value of approximately $0.05 \%$ or $0.6 \mu \mathrm{M}$ (Gupta and Igamberdiev, 2011). Gupta and Kaiser (2010) demonstrated that this process occurs in the membrane but not in the matrix of mitochondria. The complexes III and IV of the mitochondrial electron transport chain were shown to be the sites for NO production.

$$
\mathrm{NO}_{2}^{-}+2 \mathrm{H}^{+}+\mathrm{e}^{-} \rightarrow \mathrm{NO}+\mathrm{H}_{2} \mathrm{O}
$$

The complex III can produce NO via a leakage of electrons to nitrite in a similar way as superoxide is produced by oneelectron reduction of oxygen at this site. The mechanisms of nitrite reduction to $\mathrm{NO}$ by $\mathrm{COX}$ are still under investigation and several models are available for the explanation of this mechanism (reviewed in Gupta and Igamberdiev, 2011). The availability of oxygen, nitrite and NO determines the redox state of the COX center that contains heme $a_{3}$ and copper $\mathrm{B}\left(\mathrm{Fe}_{\mathrm{a} 3} \mathrm{Cu}_{\mathrm{B}}\right)$ that in turn depends on the redox state of cytochrome $c$. In the absence of oxygen, $\mathrm{Fe}^{2+}$ donates the electron for nitrite reduction to NO. But still the concrete details of this mechanism remain speculative.

Other sites of nitrite reduction to $\mathrm{NO}$ in mitochondria may include cytochrome $c$ itself and other hemeproteins (Basu et al., 2008). The proteins other than hemeproteins may also be 
involved in NO formation. The involvement of the AOX, which is a di-iron carboxylate protein, in NO production was suggested on the basis of the effect of its inhibitor, salicylhydroxamic acid (SHAM) on NO evolution from mitochondria (Planchet et al., 2005; Gupta and Kaiser, 2010). Some proteins of a similar iron structure are found to be effective in NO metabolism (Kurtz, 2007). However, NO production in alfalfa (Medicago truncatula) nodules was fully insensitive to AOX inhibitor propylgallate (Horchani et al., 2011). The effect of AOX inhibitors reported in several studies may be explained by their action on other proteins, including peroxidases and other hemeproteins (Brouwer et al., 1986).

\section{NITRITE REDUCTION TO NO LEADS TO ATP GENERATION VIA PHYTOGLOBIN-NO CYCLE}

Under anoxia mitochondria produce significant amounts of NO (Gupta et al., 2005; Planchet et al., 2005). One interesting puzzle is the physiological role of the mitochondrial NO production. Previously it was suggested that COX may play a role in membrane translocation of protons during nitrite reduction to NO (Castello et al., 2006). Isolated mitochondria of barley and rice were able oxidize the externally applied NADH and NADPH under anoxia when nitrite was applied, and this oxidation resulted in the detectable ATP formation (Stoimenova et al., 2007). The build-up of ATP during the oxidation of NADH and NADPH by anoxic mitochondria was sensitive to myxothiazol and KCN suggesting that the operation of the complexes III and IV is essential for this process. The anoxic production of ATP constituted only $3-5 \%$ of the aerobic ATP generation. However, the ATP produced during glycolytic fermentation together with the mitochondrial anaerobic nitrite-driven ATP production can make a major contribution for hypoxic survival.

The produced NO needs to be recycled very fast in order to avoid the nitrosative stress. Plants possess hypoxically induced hexacoordinated hemoglobins (called class 1 phytoglobins). They are the active scavengers of NO; thereby they can significantly reduce the amounts of NO to the levels that are much less toxic to plants. Class 1 phytoglobins possess the affinity to oxygen of two orders of magnitude higher than cytochrome $c$ oxidase $(K \mathrm{~d}$ $\sim 2 \mathrm{nM}$ ); therefore they can operate at the oxygen levels that cannot be utilized by mitochondria (Igamberdiev et al., 2011). Scavenging of NO involves the oxidation of phytoglobin ferrous ion, forming metphytoglobin and nitrate (Igamberdiev et al., 2006, 2011). Operation of the phytoglobin-NO cycle is essential for recycling nitrate and nitrite and for oxidation of excess of NADH and NADPH (Igamberdiev and Hill, 2004, 2009; Gupta and Igamberdiev, 2011; Igamberdiev et al., 2014) (Figure 1). This cycle can also contribute to $\mathrm{NAD}^{+}$recycling for the continuous operation of glycolysis. Its operation is important not only under the hypoxic conditions (that occur during germination of seeds, in flooding stress or in compact meristemic tissues) but also in the course of pathogen infection, when significant amounts of $\mathrm{NO}$ are formed during the response mediated by salicylic and jasmonic acids (Mur et al., 2012).

\section{IS NITRITE-DRIVEN ANAEROBIC ATP SYNTHESIS SUFFICIENT FOR PLANTS TO SURVIVE UNDER HYPOXIA?}

In order to survive under hypoxia and anoxia, plants need to sustain the machinery to carry out transcription and translation. It has been shown that the energy budgeting occurs under hypoxia to direct a specific amount of ATP for cellular functions (Edwards et al., 2012); at the same time cell recovery processes, such as cell division and elongation, decelerate in order to save energy (Takahashi et al., 2011). Several lines of evidence suggest that the active transcription of the mitochondrial genes takes place under hypoxia (Narsai and Whelan, 2013), while RNA translation appears to be downregulated. This was evidenced by $50 \%$ reduction in polysome content (Branco-Price et al., 2008) to reduce energy costs of unwanted translation during stress condition.

For instance, plants actively switch on the ethylene responsive transcription factors which are required for hypoxia sensing and survival (Bailey-Serres et al., 2012). In comparison to transcription, protein biosynthesis is much more energy demanding process. It has been shown that the translation of catabolic proteins takes place in anoxic coleoptiles of rice (Edwards et al., 2012). Plants invest energy in making catabolic proteins, such as the enzymes involved in glycolysis, under hypoxia/anoxia to get higher energy yield. Previously we have shown that mitochondria from roots produce $\mathrm{NO}$ within minutes of exposure to hypoxia suggesting that energy production initiation related to $\mathrm{NO}$ turnover starts within minutes. The anoxia-tolerant rice produced much higher levels of anoxic ATP in comparison to anoxia-intolerant barley suggesting essentiality of the nitrite-driven ATP production in the anoxic survival (Stoimenova et al., 2007). Since nitrate reductase (NR) is a part of the hemoglobin-NO cycle, its transcript is highly induced in anoxic rice coleoptiles (Lasanthi-Kudahettige et al., 2007). The increase of NR activity under oxygen deprivation (Planchet et al., 2005) suggests that the activation of transcription and translation of NR contributes to the excess of nitrite production and to NO generation, thus helping to improve the energy status of hypoxic plants to support the transcription and translation processes. The post-translational activation of NR under hypoxia is particularly important, which is achieved through dissociation of the 14-3-3 protein inhibitor and NR dephosphorylation (Allègre et al., 2004).

\section{ROS IN THEIR REACTION WITH NO PRODUCE REACTIVE NITROGEN SPECIES (RNS)}

Electrons enter the mitochondrial electron transport chain primarily via complex I, the alternative rotenone-insensitive dehydrogenases, and complex II (succinate dehydrogenase). These electrons are transferred to the ubiquinone pool which is a central reservoir for accumulation of electrons. From the ubiquinone pool electrons pass to complex III and complex IV, 


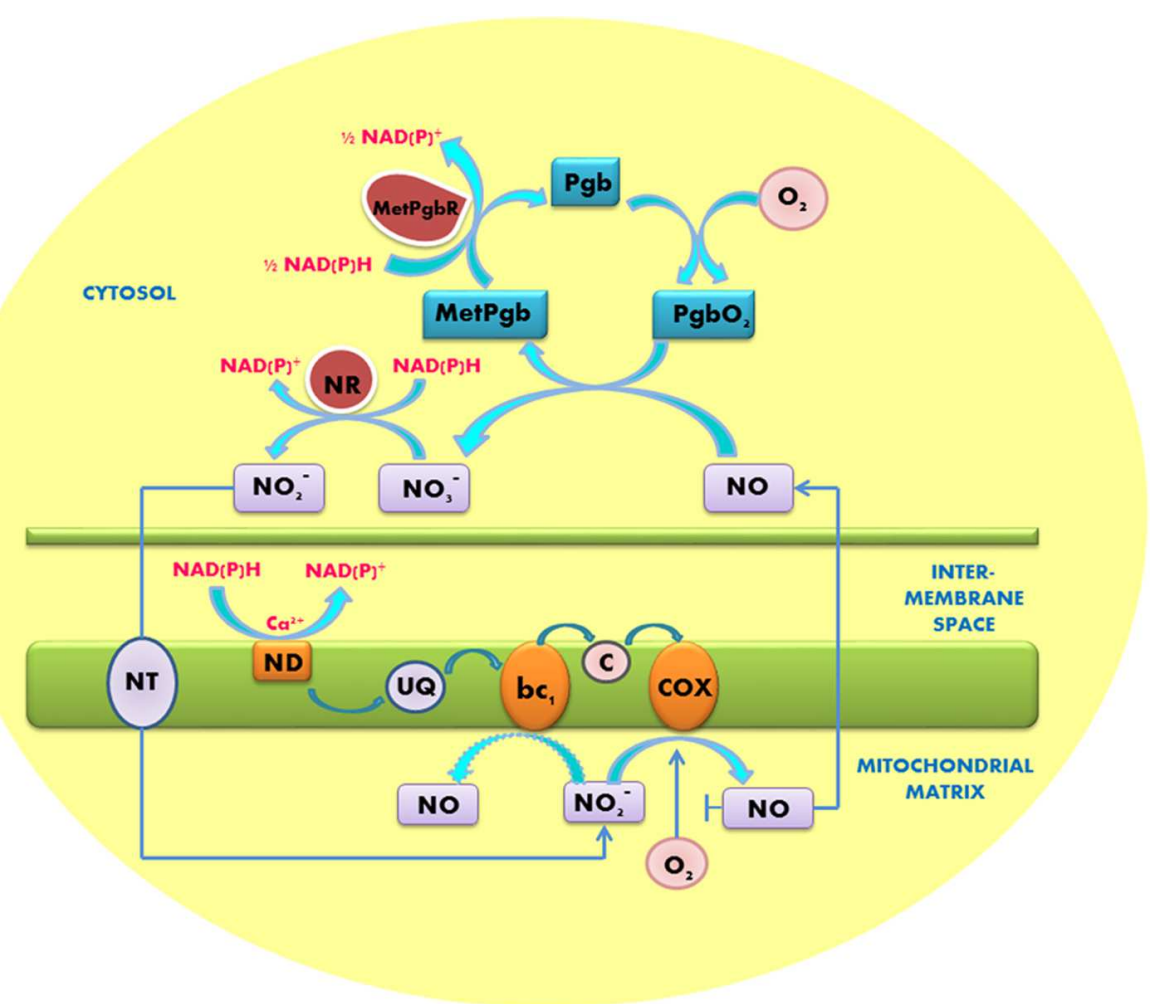

FIGURE 1 | Operation of the phytoglobin/NO cycle between the anoxic mitochondrion and cytosol. Nitrite reduction and NO formation occur at COX and complex III $\left(\mathrm{bc}_{1}\right)$. NO diffuses to the cytosol where it is converted to nitrate $\left(\mathrm{NO}_{3}{ }^{-}\right)$by the oxygenated non-symbiotic phytoglobin $\left(\mathrm{PgbO}_{2}\right)$. Metphytoglobin $(\mathrm{MetPgb})$ formed in this reaction is recycled by metphytoglobin reductase (MetPgbR) and the product nitrate is reduced by nitrate reductase (NR) to nitrite, which is transported to mitochondria by a putative nitrite transporter (NT). NAD(P)H is oxidized by the externally facing mitochondrial dehydrogenases (ND). Q, ubiquinone; c, cytochrome c. Modified from Gupta and Igamberdiev (2011).

or to the AOX. The transfer through complexes III and IV leads to the generation of electrochemical proton gradient which is used by the ATP synthase to generate ATP (Rasmusson et al., 2008). When oxygen concentrations decrease below $10 \mu \mathrm{M}$, AOX does not function due its high $\mathrm{Km}$ to oxygen, and when oxygen concentrations fall further below $1 \mu \mathrm{M}$, the operation of COX is also ceased. This leads to the accumulation of electrons in the ubiquinone pool and at the other sites such as complex I and III. This results in the condition when the remaining oxygen molecules accept only one electron which leads to the production of superoxide anion $\left(\mathrm{O}_{2}{ }^{-}\right)$. The elevated $\mathrm{NADH} / \mathrm{NAD}^{+}$ratio in the mitochondrial matrix under hypoxic conditions, becomes a condition leading to the increase in superoxide anion production even at low oxygen concentrations (Murphy, 2009). The reduced electron carrier proteins are able to react with $\mathrm{O}_{2}$ to form $\mathrm{O}_{2}{ }^{-}$, while $\mathrm{NO}$ produced under hypoxia can activate or repress these proteins to control $\mathrm{O}_{2}{ }^{-}$production. $\mathrm{NO}$ is known to inhibit respiration by competitively binding to cytochrome c oxidase (Cooper, 2002). Thus, by increasing or decreasing the rate of $\mathrm{O}_{2}$ consumption by mitochondria $\mathrm{NO}$ may influence $\mathrm{O}_{2}{ }^{-}$production in vivo by altering the local $\left[\mathrm{O}_{2}\right]$ (Borisjuk et al., 2007). Recently it was shown that the overexpression of phytoglobins leads not only to the decrease in NO but also results in the increased respiration, lowering internal oxygen concentration, and subsequent production of ROS (Gupta et al., 2014). Paradoxically, the mitochondrial $\mathrm{O}_{2}{ }^{-}$ increases in response to low oxygen levels (Chandel et al., 1998; Guzy and Schumacker, 2006).

The produced superoxide is responsible for the generation of other ROS and of RNS. For instance, superoxide dismutase converts superoxide to hydrogen peroxide which can act as a signal. Its excessive amounts lead to cytotoxicity. NO does not directly react with $\mathrm{H}_{2} \mathrm{O}_{2}$ but there are reports that $\mathrm{NO}$ can reduce $\mathrm{H}_{2} \mathrm{O}_{2}$ formation (Małolepsza and Rózalska, 2005). This can be explained, in particular, by the activation through $S$-nitrosylation of ascorbate peroxidase, which is the key enzyme participating in $\mathrm{H}_{2} \mathrm{O}_{2}$ scavenging (Correa-Aragunde et al., 2013; BegaraMorales et al., 2014; Yang et al., 2015). The reaction between superoxide and NO occurs near the diffusion controlled rates and results in the formation of peroxynitrite $\left(\mathrm{ONOO}^{-}\right)$, which is a toxic RNS form causing tyrosine nitration (Poyton et al., 2009). Peroxynitrite is formed in relatively low amounts under nonstress conditions, while under stress both NO and superoxide levels increase stimulating its formation. The biological reactions of NO and superoxide that limit their availability also constrain the amount of peroxynitrite formed. SOD competes effectively with NO for superoxide by reducing its level and decreasing the amount of peroxynitrite formed. The class 1 phytoglobin also 
decreases peroxynitrite concentration by reducing the availability of NO to react with superoxide. Peroxynitrite can be scavenged in plants via the pathway involving thioredoxin (Wulff et al., 2009), which results in its lower toxicity in plants as compared to animal tissues where its scavenging is likely limited by a side reaction of cytochrome $c$ oxidase (Pearce et al., 2002). The excess of NO under hypoxia can react with peroxynitrite resulting in the formation of non-toxic nitrogen dioxide $\left(\mathrm{NO}_{2}\right)$ and nitrite $\left(\mathrm{NO}_{2}{ }^{-}\right)$. The produced $\mathrm{NO}_{2}$ can react with $\mathrm{NO}$ which then leads to the formation of dinitrogen trioxide $\left(\mathrm{N}_{2} \mathrm{O}_{3}\right)$ which plays a role in nitrosative reactions (Espey et al., 2002).

In summary, plant mitochondria in the conditions of oxygen deficiency can reduce nitrite to NO, which can help in increasing their energy efficiency for supporting active transcription and translation processes in the hypoxic cells. NO participates in $\mathrm{NAD}^{+}$recycling via the hemoglobin-NO cycle. In the reactions

\section{REFERENCES}

Allègre, A., Silvestre, J., Morard, P., Kallerhoff, J., and Pinelli, E. (2004). Nitrate reductase regulation in tomato roots by exogenous nitrate: a possible role in tolerance to long-term root anoxia. J. Exp. Bot. 55, 2625-2634. doi: $10.1093 / j x b /$ erh258

Bailey-Serres, J., Fukao, T., Gibbs, D. J., Holdsworth, M. J., Lee, S. C., Licausi, F., et al. (2012). Making sense of low oxygen sensing. Trends Plant Sci. 17, 129-138. doi: 10.1016/j.tplants.2011.12.004

Bailey-Serres, J., and Voesenek, L. A. (2008). Flooding stress: acclimations and genetic diversity Annu. Rev. Plant Biol. 59, 313-339. doi: 10.1146/annurev.arplant.59.032607.092752

Basu, S., Azarova, N. A., Font, M. D., King, S. B., Hogg, N., Gladwin, M. T., et al. (2008) Nitrite reductase activity of cytochrome c. J. Biol. Chem. 283, 32590-32597. doi: 10.1074/jbc.M806934200

Begara-Morales, J. C., Sánchez-Calvo, B., Chaki, M., Valderrama, R., MataPérez, C., López-Jaramillo, J., et al. (2014) Dual regulation of cytosolic ascorbate peroxidase (APX) by tyrosine nitration and S-nitrosylation. J. Exp. Bot. 65, 527-538. doi: 10.1093/jxb/ert396

Borisjuk, L., Macherel, D., Benamar, A., Wobus, U., and Rolletschek, H. (2007). Low oxygen sensing and balancing in plant seeds: a role for nitric oxide. New Phytol. 176, 813-823. doi 10.1111/j.1469-8137.2007.02226.x

Botrel, A., Magne, C., and Kaiser, W. M. (1996). Nitrate reduction, nitrite reduction and ammonium assimilation in barley roots in response to anoxia. Plant Physiol. Biochem. 34, 645-652.

Branco-Price, C., Kaiser, K. A., Jang, C. J. H., Larive, C. K., and Bailey-Serres, J. (2008). Selective mRNA translation coordinates energetic and metabolic adjustment to cellular oxygen deprivation and reoxygenation in Arabidopsis thaliana. Plant J. 56, 743-755. doi: 10.1111/j.1365-313X.2008.03642.x

Brouwer, K. S., van Valen, T., Day, D. A., Lambers, H. (1986) Hydroxamatestimulated $\mathrm{O}_{2}$ uptake in roots of Pisum sativum and Zea mays, mediated by a peroxidase: its consequences for respiration measurements. Plant Physiol. 82, 236-240. doi: 10.1104/pp.82.1.236

Castello, P. R., David, P. S., McClure, T., Crook, Z., and Poyton, R. O. (2006). Mitochondrial cytochrome oxidase produces nitric oxide under hypoxic conditions: implications for oxygen sensing and hypoxic signaling in eukaryotes. Cell Metabol. 3, 277-287. doi: 10.1016/j.cmet.2006. 02.011

Chandel, N. S., Maltepe, E., Goldwasser, E., Mathieu, C. E., Simon, M. C., and Schumacker, P. T. (1998). Mitochondrial reactive oxygen species trigger hypoxia-induced transcription. Proc. Natl. Acad. Sci. U.S.A. 95, 11715-11720. doi: $10.1073 /$ pnas.95.20.11715

Cooper, C. E. (2002). Nitric oxide and cytochrome oxidase: substrate, inhibitor or effector? Trends Biochem. Sci. 27, 33-39. doi: 10.1016/S0968-0004(01)02035-7

Correa-Aragunde, N., Foresi, N., Delledonne, M., Lamattina, L. (2013) Auxin induces redox regulation of ascorbate peroxidase 1 activity by S-nitrosylation/denitrosylation balance resulting in changes of root with ROS, NO forms peroxynitrite and other RNS such as $\mathrm{N}_{2} \mathrm{O}_{3}$ which play a role as signals during the nitrosative stress.

\section{AUTHOR CONTRIBUTIONS}

All authors listed, have made substantial, direct and intellectual contribution to the work, and approved it for publication.

\section{ACKNOWLEDGMENTS}

This work was supported by the grants from the Ramalingaswami fellowship and IYBA award by Department of Biotechnology, Govt. of India (to KG) and from the National Science and Engineering Research Council of Canada (to AI).

growth pattern in Arabidopsis. J. Exp. Bot. 64, 3339-3349. doi: 10.1093/jxb/ ert172

Coueé, I., Defontaine, S., Carde, J. P., and Pradet, A. (1992). Effects of anoxia on mitochondrial biogenesis in rice shoots - modification of in organello translation characteristics. Plant Physiol. 98, 411-421. doi: 10.1104/pp.98. 2.411

Dechorgnat, J., Nguyen, C. T., Armengaud, P., Jossier, M., Diatloff, E., Filleur, S., et al. (2011). From the soil to the seeds: the long journey of nitrate in plants. J. Exp. Bot. 62, 1349-1359. doi: 10.1093/jxb/erq409

Edwards, J. M., Roberts, T. H., and Atwell, B. J. (2012). Quantifying ATP turnover in anoxic coleoptiles of rice (Oryza sativa) demonstrates preferential allocation of energy to protein synthesis. J. Exp. Bot. 63, 4389-4402. doi: $10.1093 / \mathrm{jxb} / \mathrm{ers} 114$

Espey, M. G., Thomas, D. D., Miranda, K. M., and Wink, D. A. (2002). Focusing of nitric oxide mediated nitrosation and oxidative nitrosylation as a consequence of reaction with superoxide. Proc. Natl. Acad. Sci. U.S.A. 99, 11127-11132. doi: 10.1073/pnas.152157599

Gupta, K. J., Hebelstrup, K. H., Kruger, N. J., and Ratcliffe, R. G. (2014). Nitric oxide is required for homeostasis of oxygen and reactive oxygen species in barley roots under aerobic conditions. Mol. Plant 7, 747-750. doi: 10.1093/mp/ sst167

Gupta, K. J., and Igamberdiev, A. U. (2011). The anoxic plant mitochondrion as a nitrite: NO reductase. Mitochondrion 11, 537-543. doi: 10.1016/j.mito.2011.03.005

Gupta, K. J., and Kaiser, W. M. (2010). Production and scavenging of nitric oxide by barley root mitochondria. Plant Cell Physiol. 51, 576-584. doi: $10.1093 / \mathrm{pcp} / \mathrm{pcq} 022$

Gupta, K. J., Stoimenova, M., and Kaiser, W. M. (2005). In higher plants, only root mitochondria, but not leaf mitochondria reduce nitrite to NO, in vitro and in situ. J. Exp. Bot. 56, 2601-2609. doi: 10.1093/jxb/eri252

Guzy, R. D., and Schumacker, P. T. (2006). Oxygen sensing by mitochondria at complex III: the paradox of increased reactive oxygen species during hypoxia. Exp. Physiol. 91, 807-819. doi: 10.1113/expphysiol.2006.033506

Horchani, F., Prevot, M., Boscari, A., Evangelisti, E., Meilhoc, E., Bruand, C., et al. (2011) Both plant and bacterial nitrate reductases contribute to nitric oxide production in Medicago truncatula nitrogen-fixing nodules. Plant Physiol. 155, 1023-1036. doi: 10.1104/pp.110.166140

Howell, K. A., Cheng, K., Murcha, M. W., Jenkin, L. E., Millar, A. H., and Whelan, J. (2007). Oxygen initiation of respiration and mitochondrial biogenesis in rice. J. Biol. Chem. 282, 15619-15631. doi: 10.1074/jbc.M609866200

Igamberdiev, A. U., Bykova, N. V., and Hill, R. D. (2006). Nitric oxide scavenging by barley hemoglobin is facilitated by a monodehydroascorbate reductasemediated ascorbate reduction of methemoglobin. Planta 223, 1033-1040. doi: 10.1007/s00425-005-0146-3

Igamberdiev, A. U., Bykova, N. V., and Hill, R. D. (2011). Structural and functional properties of class 1 plant hemoglobins. IUBMB Life 63, 146-152. doi: 10.1002/iub.439 
Igamberdiev, A. U., and Hill, R. D. (2004). Nitrate, NO and haemoglobin in plant adaptation to hypoxia: an alternative to classic fermentation pathways. J. Exp. Bot. 55, 2473-2482. doi: 10.1093/jxb/erh272

Igamberdiev, A. U., and Hill, R. D. (2009). Plant mitochondrial function during anaerobiosis. Ann. Bot. 103, 259-268. doi: 10.1093/aob/mcn 100

Igamberdiev, A. U., Ratcliffe, R. G., and Gupta, K. J. (2014). Plant mitochondria: source and target for nitric oxide. Mitochondrion 19B, 329-333. doi: 10.1016/j.mito.2014.02.003

Kennedy, R. A., Fox, T. C., and Siedow, J. N. (1987). Activities of isolated mitochondria and mitochondrial enzymes from aerobically and anaerobically germinated barnyard grass (Echinochloa) seedlings. Plant Physiol. 85, 474-480. doi: $10.1104 / p p .85 .2 .474$

Kozlov, A. V., Staniek, K., and Nohl, H. (1999). Nitrite reductase activity is a novel function of mammalian mitochondria. FEBS Lett. 454, 127-130. doi: 10.1016/S0014-5793(99)00788-7

Kurtz, D. M. (2007) Flavo-diiron enzymes: nitric oxide or dioxygen reductases? Dalton Trans. 37, 4115-4121. doi: 10.1039/b710047g

Lasanthi-Kudahettige, R., Magneschi, L., Loreti, E., Gonzali, S., Licausi, F., Novi, G., et al. (2007). Transcript profiling of the anoxic rice coleoptile. Plant Physiol. 144, 218-231. doi: 10.1104/pp.106.093997

Laus, M. N., Soccio, M., Trono, D., Cattivelli, L., and Pastore, D. (2008). Plant inner membrane anion channel (PIMAC) function in plant mitochondria. Plant Cell Physiol. 49, 1039-1055. doi: 10.1093/pcp/pcn082

Małolepsza, U., and Rózalska, S. (2005). Nitric oxide and hydrogen peroxide in tomato resistance. Nitric oxide modulates hydrogen peroxide level in o-hydroxyethylorutin-induced resistance to Botrytis cinerea in tomato. Plant Physiol. Biochem. 43, 623-635. doi: 10.1016/j.plaphy.2005.04.002

Müller, E., Albers, B., and Janiesch, P. (1994). Influence of $\mathrm{NO}_{3}$ - and $\mathrm{NH}_{4+}$ nutrition on fermentation, nitrate reductase activity and adenylate energy charge of roots of Carex pseudocyperus L. and Carex sylvatica Huds. exposed to anaerobic nutrient solutions. Plant Soil 166, 221-230. doi: 10.1007/BF000 08335

Mur, L. A., Sivakumaran, A., Mandon, J., Cristescu, S. M., Harren, F. J., Hebelstrup, K. H. (2012) Haemoglobin modulates salicylate and jasmonate/ethylenemediated resistance mechanisms against pathogens. J. Exp. Bot. 63, 4375-4387. doi: $10.1093 / \mathrm{jxb} / \mathrm{ers} 116$

Murphy, M. P. (2009). How mitochondria produce reactive oxygen species. Biochem. J. 417, 1-13. doi: 10.1042/BJ20081386

Narsai, R., and Whelan, J. (2013). How unique is the low oxygen response? An analysis of the anaerobic response during germination and comparison with abiotic stress in rice and Arabidopsis. Front. Plant Sci. 4:349. doi: 10.3389/fpls.2013.00349

Palmieri, F., Pierri, C. L., De Grassi, A., Nunes-Nesi, A., Fernie, A. R. (2011) Evolution, structure and function of mitochondrial carriers: a review with new insights. Plant J. 66, 161-181. doi: 10.1111/j.1365-313X.2011. 04516.x

Pearce, L. L., Kanai, A. J., Birder, L. A., Pitt, B. R., and Peterson, J. (2002). The catabolic fate of nitric oxide: the nitric oxide oxidase and peroxynitrite reductase activities of cytochrome oxidase. J. Biol. Chem. 277, 13556-13562. doi: 10.1074/jbc.M109838200

Planchet, E., Gupta, K. J., Sonoda, M., and Kaiser, W. M. (2005). Nitric oxide emission from tobacco leaves and cell suspensions: rate limiting factors and evidence for the involvement of mitochondrial electron transport. Plant J. 41, 732-743. doi: 10.1111/j.1365-313X.2005.02335.x

Poyton, R. O., Ball, K. A., and Castello, P. R. (2009). Mitochondrial generation of free radicals and hypoxic signaling. Trends Endocrinol. Metab. 20, 332-340. doi: 10.1016/j.tem.2009.04.001

Rasmusson, A. G., Geisler, D. A., and Møller, I. M. (2008). The multiplicity of dehydrogenases in the electron transport chain of plant mitochondria. Mitochondrion 8, 47-60. doi: 10.1016/j.mito.2007.10.004
Salvato, F., Havelund, J. F., Chen, M., Rao, R. S., Rogowska-Wrzesinska, A., Jensen, O. N., et al. (2014). The potato tuber mitochondrial proteome. Plant Physiol. 164, 637-653. doi: 10.1104/pp.113.229054

Shingaki-Wells, R., Millar, A. H., Whelan, J., Narsai, R. (2014). What happens to plant mitochondria under low oxygen? An omics review of the responses to low oxygen and reoxygenation. Plant Cell Environ. 37, 2260-2277. doi: $10.1111 /$ pce. 12312

Simontacchi, M., Galatro, A., Ramos-Artuso, F., and Santa-María, G. E. (2015). Plant survival in a changing environment: the role of nitric oxide in plant responses to abiotic stress. Front. Plant Sci. 6:977. doi: 10.3389/fpls.2015.00977

Stoimenova, M., Igamberdiev, A. U., Gupta, K. J., and Hill, R. D. (2007). Nitritedriven anaerobic ATP synthesis in barley and rice root mitochondria. Planta 226, 465-474. doi: 10.1007/s00425- 007-0496-0

Sugiura, M., Georgescu, M. N., and Takahashi, M. (2007). A nitrite transporter associated with nitrite uptake by higher plant chloroplasts. Plant Cell Physiol. 48, 1022-1035. doi: 10.1093/pcp/pcm073

Takahashi, H., Saika, H., Matsumura, H., Nagamura, Y., Tsutsumi, N., Nishizawa, N. K., et al. (2011). Cell division and cell elongation in the coleoptile of rice alcohol dehydrogenase 1-deficient mutant are reduced under complete submergence. Ann. Bot. 108, 253-261. doi: 10.1093/aob/mcr137

Taylor, N. L., Howell, K. A., Heazlewood, J. L., Tan, T. Y., Narsai, R., Huang, S., et al. (2010). Analysis of the rice mitochondrial carrier family reveals anaerobic accumulation of a basic amino acid carrier involved in arginine metabolism during seed germination. Plant Physiol. 154, 691-704. doi: 10.1104/pp.110.162214

Tielens, A. G. M., Rotte, C., van Hellemond, J. J., and Martin, W. (2002). Mitochondria as we don't know them. Trends Biochem. Sci. 27, 564-572. doi: 10.1016/s0968-0004(02)02193-x

Tischner, R., Planchet, E., and Kaiser, W. M. (2004). Mitochondrial electron transport as a source for nitric oxide in the unicellular green alga Chlorella sorokiniana. FEBS Lett. 576, 151-155. doi: 10.1016/.febslet.2004.09.004

Tschiersch, H., Borisjuk, L., Rutten, T., and Rolletschek, H. (2011). Gradients of seed photosynthesis and its role for oxygen balancing. Biosystems 103, 302-308. doi: 10.1016/j.biosystems.2010.08.007

Vartapetian, B. B., Andreeva, I. N., Generozova, I. P., Polyakova, L. I., Maslova, I. P., Dolgikh, Y. I., et al. (2003). Functional electron microscopy in studies of plant response and adaptation to anaerobic stress. Ann. Bot. 91, 155-172. doi: 10.1093/aob/mcf244

Vartapetian, B. B., and Polyakova, L. I. (1999). Protective effect of exogenous nitrate on the mitochondrial ultrastructure of Oryza sativa coleoptiles under strict anoxia. Protoplasma 206, 163-167. doi: 10.1007/BF01279263

Wulff, A., Oliveira, H. C., Saviani, E. E., and Salgado, I. (2009). Nitrite reduction and superoxide-dependent nitric oxide degradation by Arabidopsis mitochondria: influence of external $\mathrm{NAD}(\mathrm{P}) \mathrm{H}$ dehydrogenases and alternative oxidase in the control of nitric oxide levels. Nitric Oxide 21, 132-139. doi: 10.1016/j.niox.2009.06.003

Yang, H., Mu, J., Chen, L., Feng, J., Hu, J., Li, L., et al. (2015). S-nitrosylation positively regulates ascorbate peroxidase activity during plant stress responses. Plant Physiol. 167, 1604-1615. doi: 10.1104/pp.114.255216

Conflict of Interest Statement: The authors declare that the research was conducted in the absence of any commercial or financial relationships that could be construed as a potential conflict of interest.

Copyright $\odot 2016$ Gupta and Igamberdiev. This is an open-access article distributed under the terms of the Creative Commons Attribution License (CC BY). The use, distribution or reproduction in other forums is permitted, provided the original author(s) or licensor are credited and that the original publication in this journal is cited, in accordance with accepted academic practice. No use, distribution or reproduction is permitted which does not comply with these terms. 